\title{
Sustainability of micro-enterprises in the digital economy
}

\author{
Oksana Mukhoryanova ${ }^{1}$, Larisa Kuleshova $^{2}$, Nina Rusakova $^{3}$, and Olga Mirgorodskaya ${ }^{4}$ \\ ${ }^{1}$ North-Caucasus Federal University, Pushkin str., 1, Stavropol, 355009, Russian Federation \\ ${ }^{2}$ Stavropol State Agrarian University, Zootechnical line, Stavropol, 355017, Russian Federation \\ ${ }^{3}$ Rostov State Transport University, Rostov Rifle Regiment of the People's Militia Square, house 2, \\ Rostov-on-Don, 344038, Rostov Region, Russian Federation \\ ${ }^{4}$ Stavropol Institute of Cooperation (branch) of BUKEP, Stavropol, Goleneva str., 36, Stavropol, \\ 355035, Russian Federation
}

\begin{abstract}
This paper aims at investigating the predisposition leading to the sustainability of micro-enterprises in the digital economy, especially the sharing economy. This area represents a new field since the research of the impact of the sharing economy on small enterprises is still in its infancy. We study the role of the entrepreneurial approach and entrepreneurial philosophy of the small business with regard to the digitalization and the sustainable development and growth using examples from the European Union and the United States. Some common features and trends are derived and the outcomes are discussed. Our results point at the fact that by creating an economy for micro-entrepreneurs, the sharing economy thrives on traditional industry disrupted by technology. Since micro-enterprises constitute a backbone of the economy in many developed and developing countries, more research is required to shed the light of the sustainable development of these types of enterprises in the globalized and digitalized world.
\end{abstract}

\section{Introduction}

Generally, micro and small entrepreneurs still do not see environmental management as a strategy for innovation that can help increase the profitability of the organisation and thus ensure its survival in the market $[1,2]$. Small business has no incentive to meet environmental standards despite the growing market demand for sustainable business practices. A culture of innovation plays a crucial role in maintaining a company's competitiveness [3, 4]. For micro and small enterprises, this role is perceived as much more important, as it contributes to a longer life of the company by helping to reduce its fragility. Small and medium-sized enterprises have one major advantage over larger organisations when it comes to solving sustainability issues [5-7]. This means that they can react very quickly to changes in the business environment. While some enterprises are leaders in sustainable practices, others lack a strategic attitude that sees changes in the business environment as an opportunity rather

\footnotetext{
*Corresponding author: omukhorianova@ncfu.ru
} 
than an additional burden on the task that requires further change. There are market changes that create sustainability opportunities for innovation and inspiration for employees.

Generally, the innovation process in this environment has emerged as a factor that can be crucial for the survival of micro and small enterprises. Environmental certification cane become an opportunity for small and medium-sized enterprises to prove their ability to enter new markets and to be competitive and recognized as environmentally friendly enterprises $[8,9]$. What motivates those seeking official recognition is the legitimacy of what the competitive divide seeks to represent. Innovation in this environment is an instrument that can help small businesses to adhere to environmentally friendly production processes, but without significantly increasing their production and marketing costs. In the current market scenario, micro and small enterprises have adapted to the constant change and invested in innovation. The innovation process has proved to be a factor that has helped companies to hold their own and gain ground in increasingly competitive markets. On the contrary, the goal is to increase profits through sustainable production, and changes in corporate behaviour have taken place to not only increase profitability, but also ensure the survival of the market [10].

Management and control mechanisms influence the way companies produce and enable them to purchase new machinery that helps reduce pollutant emissions and enable them to produce products through environmentally sound extraction of raw materials. In this scenario, it is crucial to include micro and small enterprises in the products and services offered to consumers. As companies invest in environmental certification, competition differences become a growing demand for their products and a competitive gap becomes an incentive for companies to invest in environmental certification. Therefore, it is required to define the role of micro and small enterprises for the sustainability of the global economy and to bring their relevance to this scenario. Stakeholders are promoting the need to educate micro and small entrepreneurs about ways to increase profitability and protect our environment. The Rio de Janeiro Conference back in 1992 discussed the need to link our society's attitude to environmental issues and to create companies charged with ecologically sound production and marketing. With the growing trend of recent years, the organization can increase the sustainability of small businesses in the market by developing a sustainable business model $[11,12]$. Environmental management practice has become a contribution to the transformation of the production process, which aims to ensure the sustainability of the environment and the health and well-being of people. These standards are based on the requirements of the United States Environmental Protection Agency (EPA) and the United Nations Environment Programme (UNEP). This change in position affects the strategic role that environmental management plays in our society, even if it is seen as a means of profitmaking for capitalist systems $[13,14]$.

As mentioned above, we believe that it is crucial for public policy to encourage microenterprises to comply with environmental standards and to introduce environmental certificates, as these measures contribute to the survival of businesses and the preservation of the environment. In short, there is an urgent need to create a global movement for sustainability and allied innovation in the production process. If environmental certification is introduced but companies do not want to be certified, certification can be a factor that excludes them from the market.

\section{Uberization of economy and economic systems}

Currently, many researchers write about the "uberization" of the economy $[15,16]$. It is symptomatic that the process of regulating joint enterprise activities is subject to constant review, based on empirical evidence that is exemplary in urban policies on Uber, a taxihailing app. The complexity and differentiation of sharing practices has gripped the entire 
urban economy, extending beyond selected sectors to activities that are not limited to traditional modes of transportation, but also include activities such as sharing scooters, originally designed for last-mile commuting.

The sharing economy can be used as an attribute of the city, where innovation thrives and leads to the creation of a common city and a new form of economic and social norms. Together with increased user protection, the economic benefits of sharing, combined with increased user protection, will contribute to the growth of the community and the sharing of these services, leading to faster growth and adoption of values that make sharing a social norm $[17,18]$. One can emphasize the new position of the consumer in the sharing economy by defining him as a consumer who grants physical assets to each other, possibly in exchange for money. The benefits and access for consumers are that the sharing economy uses digital platforms to provide customers with access to a wide range of services such as transport, food, clothing and other goods and services. The European Union uses the term "collective consumption" as a reference to the changes that are coming with the emergence of a sharing paradigm [19]. To capitalise on the untapped capacity for trust and verification, the specifications of this new market must ensure that buyers and sellers are aligned. The digitally managed peer-to-peer nature of the sharing economy does not fit well with current laws and regulations.

Sharing economy services do not have to comply with certain rules, which, on the other hand, helps to make the services provided more affordable. This business model has had many growing problems and many ordinary employees have tried to stop the growth of business models. Many are not ready to switch to a model where others already use more than four platforms in their daily lives. Taxi services now have apps that allow consumers to call a car and pay for it, as with Uber and Lyft [20]. Sharing economy platforms can also popularise the use of transit and accommodation services and drive existing companies out of the market. For example, there were protests in Spain in the late 1990s and early 2000s, which turned quite violent at times. Spain has been more or less paralysed by the collapse of the taxi industry and the rise of private taxi companies such as Uber. This is because Uber offers a platform on which other companies can build, such as a fleet of pizza delivery vehicles. It seems that the rise of Uber has changed that, and that Uber is increasing the pie rather than cutting a thin slice of it. In addition to the algorithmic structure that Uber and other sharing economy platforms offer, companies operating on these platforms should also be considered as separate "Uber companies." The collection, processing and use of personal information is the closest study of consumers by digital and physical companies such as Uber and other companies [21].

Digital platforms facilitated by the Internet, such as social media, social networks, mobile apps, cloud computing, data analysis, etc., are restructuring more and more parts of the economy. But as we will examine in the next part, what we share may be more important than what is shared, and there is a reason for that. Just as people who raise privacy concerns about Uber and Airbnb (a property renting app) do so for the same reasons as those who raise privacy concerns about Facebook and Google, so do people who raise privacy concerns about Airbnb [22].

The promise of the sharing economy, rhetorically based on the idea of social reciprocity, continues today. Airbnb, for example, claims to be a community wherever a marketplace is created, where hosts auction off their vacant rooms to tourists. Uber helps underserved communities provide an alternative to more efficient transit access. The sharing economy is a bit difficult to define, but one definition can be defined roughly as one sees it here: you pay to access or rent an object, such as a condo, on Airbnb through an online marketplace.

All in all, trust in the economic community enables trade, while at the same time responding to the needs of local communities and even addressing historical injustices. The sharing economy enables the gig economy, in which people make money by doing a series 
of small jobs or "gigs." At first, performing meant paid work, such as musical engagements, which could range from a single musical performance of just one night to much more.

\section{Sharing economy and micro-enterprises}

Broadly speaking, sharing economy literally produces a vast quantity of microentrepreneurs. These entrepreneurs often start with a few hundred dollars or less in capital and are often in the early stages of their business. Many of the investors agree with the moral vision of a sharing economy [23].

Then, it is about drawing up a business plan to start in the shared economy, which is very different from traditional business models such as traditional taxi business, with very little traditional financial support, let alone taxes. The micro-entrepreneurs who make the most money on sharing platforms are also those with assets that are often rented out by similarly wealthy people. As for the cold hard net worth, the sharing economy has done little to bridge the wealth gap. It has raised working-class living standards by making it affordable for them to earn an additional income. Today, it is the second largest source of income in the United States, and is expected to be worth $\$ 335$ billion by 2025 [24].

Sharing economy not only encourages micro-entrepreneurs, but also facilitates the creation of new jobs where there were none before. Faced with the ripple effects of the recession, more consumers are turning to the sharing economy to test the entrepreneurial potential. There is no doubt that certain technology companies are beginning to develop tools to democratize their software and applications to help the shared economy thrive in an ecosystem that could potentially be anyone's game. For consumers, entrepreneurs and businesses alike, the introduction of democratized access and control could potentially disrupt an already disruptive economy.

The network, which we call the "sharing economy," allows people to exchange material and immaterial goods on a large scale. Exchanging relationships undermines traditional retail employment by reducing transactional friction. The sharing economy lacks a common definition, but it is probably more accurate to divide it into several coherent but distinct areas. One can share the same office space with dozens of different companies, get unsecured personal loans directly from her colleagues, and stay with a stranger instead of a hotel when she travels outside the city. At least some variation in the sharing economy's themes is integrated into daily life, from the growing army of people who regularly use Uber to the proliferation of social networks like Facebook and Twitter.

When viewed from the perspective of those providing services, it is often argued that collaborative trading platforms have opened up the possibility for individuals to monetize previously untapped assets. Likewise, there are millions of people who use the services they buy and consume, such as food, clothing and other goods and services. While it is surely true that an increasing number of people are making decent money by renting spare rooms to travellers or offering inner-city commuters parking, cynics argue that the financial benefits for most sharing economy providers are limited.

In addition, there is also a considerable social and environmental impact of the sharing economy, showing that the sharing economy goes much further - and is more far-reaching than ever. Sharing and its effects are now a global phenomenon and could make an important contribution to combating climate change [25]. There are traditional defenders of the economy, but ultimately the battle is between asset owners and consumers. In short, sharing economy is very beneficial for micro-companies and sole traders since it reduces the transaction and incumbent costs allowing them to concentrate on their sustainable agenda and get rid off the redundant administration and red tape. 


\section{Entrepreneurial behaviour models and Internet platforms}

Currently, very little is known about the entrepreneurial behaviour of individuals who start new businesses. To understand the factors that drive individuals to start a new business, this study attempts to assess these locations. In addition, it is interesting to follow the introduction on the entrepreneurship's intentions as assessed using concepts and theories contained in the IT deployment literature. Based on an analysis of the impact of the use of social media as a business platform on business activities and the factors influencing business intentions, a number of factors considered relevant to their impact on business intentions can be singled out. The perceived desirability is the factor that leads a person to start a business, whether that factor is intrapersonal, extra - personal or both [26, 27].

In recent decades, the development of the Internet the way people communicate and do business. The perceived feasibility indicates the degree to which the individual feels comfortable when starting his individual project, and the attitude to the expected returns is taken into account. As such sites have reached their peak popularity, their trends have evolved and flourished in recent years. Companies that focus on social media, social networks, web design, business development, and marketing include venture capital, venture capital and risk management using forecasting models. Harnessing AI's automation and forecasting capabilities can facilitate the process of venture capital creation by accelerating market studies and product testing, automating data collection through social media, and improving market targeting and positioning. A concrete example is a biotechnology company that improves the performance of research and development by using predictive models to find candidate molecules with optimal properties and then test large samples of these molecules. In this case, artificial intelligence has significantly reduced the company's research and development costs and also accelerated the time to market for its new product [28].

All these problems encourage marketers to find new ways to integrate digital technologies into market development. Since the 2010s, marketing automation has developed in response to a constantly changing marketing climate. Consumers have become increasingly aware of the importance of social media, social networks and other digital platforms for marketing and advertising. In addition, consumers are expected to search social media sites such as Facebook, Twitter, YouTube, Pinterest, Instagram and other social networks for product information. Video is also a powerful tool, but it is also increasingly being used in conjunction with social media by B2B companies looking to increase leads and conversions. While video is a great way to share product information, using video during the buyer's journey can also help companies further qualify B2B sales management capabilities [29].

All in all, social media, blogs and forums are all tools that companies can use to communicate effectively with customers. Businesses really benefit from building a strong customer network, so might be really important for companies to improve the way they identify customer problems and offer solutions that build trust and honest relationships with customers. Communication and networking also help to implement business-to-business communication and customer relationship management strategies for companies [30].

Social media has changed the way we communicate with some of the most commonly used business applications on social media such as recruiting, building employee engagement and communication, and expanding employee learning opportunities. Another important application of social media for employers is the use of the employee level as a platform for knowledge exchange. This can be presented in the form of a social network, with a focus on business-to-business communication, customer relationship management and networking. Social media can be turned into a collaborative tool to improve the workflow of work products, with an emphasis on collaboration, communication, collaboration and information exchange. 


\section{Conclusions}

The impact of a strong economy on small businesses is twofold: as business activity increases, so does the ability of small businesses to keep pace with demand by hiring additional staff, expanding sales space, and adding new product lines. This may be seen as a positive, but the downside is that many smaller companies feel overwhelmed when the economy falters, which can lead to mass layoffs and company bankruptcies. Consumers worry about job stability and are likely to be wary of spending that will reduce income for small business owners. Slow profits can make it difficult for small businesses to repay creditors, which can have a negative impact on their long-term viability.

In general terms, the impact of small businesses has broader economic implications for at least two reasons. On the one hand, small businesses are an important route to economic mobility; they enable entrepreneurial individuals to become economically independent. This environment could make the economy more stable and less vulnerable to economic downturns such as a recession. Although the role that start-ups and young technology companies play in job creationism well documented, their contribution to overall productivity has not been widely discussed or even considered. Between the two, small businesses employ nearly half of the U.S. workforce and account for more than one-third of all new jobs in the United States. Translating ideas into the new products and services that people need is the source of prosperity in the developed world.

In order to better understand how innovation contributes to economic development, we have unpacked some examples below. Workers lose their jobs at any given time, but small firms bring more jobs into the economy than they are taken away, resulting in a net increase in the number of workers. If a small business has a low survival or expansion rate, the growth rate of a given year, or even of the economy as a whole, depends on a number of factors. The economy is at the top of the list and is the most important factor for small businesses. Consumer confidence is an economic indicator that measures consumers' overall optimism about the state of the economy. Confident consumers tend to spend and are more likely to be in business, meaning that a business is more likely to thrive when consumer confidence is high. Economic factors that often influence companies include the number of jobs, the size of their workforce, and the level of investment in their business. While periods of low confidence can force a company to cut costs to maintain its profits, a period of high consumer confidence offers an opportunity for new companies to enter the market. There is a continuous positive relationship between consumer confidence and the number of small businesses in the United States. In recent years, entrepreneurship has contributed significantly to the economic growth and stability of developing countries. Financial inclusion and access to finance can be crucial to enhancing entrepreneurship's capacity to promote economic growth and accelerate the achievement of the SDGs in developing countries. Entrepreneurship, when properly exploited, can trigger economic development in emerging economies such as Africa, Asia, and the Middle East. The economic environment plays a key role in determining the success or failure rate of entrepreneurial efforts. In addition to the economic conditions of a country's economy, the economic environment can also determine the success or failure rates of entrepreneurship. Governance is an important factor in the decline in small business success rates, which further supports the findings of this study. If this decline is not reversed, it could have a disturbing impact on economic dynamism and growth. Recent studies show a strong correlation between governance and the success or failure rate of entrepreneurship in a country.

Although small businesses do not have a significant impact on employment growth, new businesses account for more than half of all jobs all around the world. Over the past three decades, companies that are less than a year old have created more jobs than any other type of business, such as hotels, restaurants, and retail stores. Only a small share of all new start- 
ups in the data make an important contribution to the economy. Large companies, on the other hand, have the resources to finance growth in difficult times and, of course, have a greater capacity to create new jobs and job opportunities at national level. Financial transaction data show that, despite the commonly held view that companies that grow with external financing make the biggest contribution to the economy, organic growth companies also make a significant contribution. Thence, governments should start creating an economy for micro-entrepreneurs that would employ the modern trends and tools such as the sharing economy that are powered by novel technologies and approaches. All of these would lead to the creation of the new class of the sustainable and digital micro-enterprises and would results in the increasing energy efficiency and the transition to the green economy.

\section{References}

1. A. Kasim, Y. Ekinci, L. Altinay, K. Hussain, Journal of Hospitality Marketing \& Management, 27(7), 855-875 (2018)

2. J. Tidd, J. Bessant, Managing innovation: integrating technological, market and organizational change (2020)

3. W. Strielkowski, M. Krejcí, I. Čabelková, Business: Theory and Practice 16(3), 304-315 (2015)

4. W. Ashton, S. Russell, E. Futch, Journal of environmental planning and management, 60(12), 2133-2149 (2017)

5. D. Rita, F. Ferreira, I. Meidutè-Kavaliauskienè, K. Govindan, J. Ferreira, Journal of Cleaner Production, 196, 985-996 (2018)

6. X. Liang, X. Zhao, M. Wang, Z. Li, Sustainability, 10(11), 4242 (2018)

7. L. Johnstone, P. Hallberg, Journal of environmental management, 266, 110592 (2020)

8. G. Santoro, R. Quaglia, A. Pellicelli, P. De Bernardi, Technological Forecasting and Social Change, 151, 119820 (2020)

9. E. Kraemer-Mbula, E. Lorenz, L. Takala-Greenish, O. Jegede, T. Garba, M. Mutambala, T. Esemu, International Journal of Technological Learning, Innovation and Development, 11(1), 1-30 (2019)

10. S. Chege, D. Wang, Technology in Society, 60, 101210 (2020)

11. M. Bengtsson, E. Alfredsson, M. Cohen, S. Lorek, P. Schroeder, P. Sustainability Science, 13(6), 1533-1547 (2018)

12. B. Todeschini, M. Cortimiglia, D. Callegaro-de-Menezes, A. Ghezzi, Business Horizons, 60(6), 759-770 (2017)

13. J. Lu, L. Ren, S. Yao, J. Qiao, W. Strielkowski, J. Streimikis, Energies, 12(18), 3417 (2019)

14. C. Haibo, E. Ayamba, A. Agyemang, S. Afriyie, A. Anaba, Environmental Science and Pollution Research, 26(7), 7228-7242 (2019)

15. P. Fleming, Organization Studies, 38(5), 691-709 (2017)

16. A. Gandini, Human Relations, 72(6), 1039-1056 (2019)

17. M. Ritter, H. Schanz, Journal of Cleaner Production, 213, 320-331 (2019)

18. M. Hossain, Sharing economy: A comprehensive literature review. International Journal of Hospitality Management, 87, 102470 (2020)

19. A. Davies, B. Donald, M. Gray, J. Knox-Hayes, Cambridge Journal of Regions, Economy and Society, 10(2), 209-230 (2017)

20. M. Pouri, L. Hilty, Environmental Innovation and Societal Transitions, 38, 127-139 (2021)

21. P. Diamandis, S. Kotler, The future is faster than you think: how converging technologies are transforming business, industries, and our lives (2020)

22. S. Nambisan, M. Wright, M. Feldman, Research Policy, 48(8), 103773 (2019) 
23. S. Chai, M. Scully, Journal of Business Ethics, 159(4), 943-960 (2019)

24. S. Ganapati, C. Reddick, Government Information Quarterly, 35(1), 77-87 (2018)

25. S. Gössling, C. Michael Hall, Journal of Sustainable Tourism, 27(1), 74-96 (2019)

26. H. Zaheer, Y. Breyer, J. Dumay, Technological Forecasting and Social Change, 148, 119735 (2019)

27. V. Ahuja, A. Akhtar, O. Wali, Journal of Global Entrepreneurship Research, 9(1), 1-27 (2019)

28. A. Oliveira, Biotechnology journal, 14(8), 1800613 (2019)

29. J. Paschen, M. Wilson, J. Ferreira, Business Horizons, 63(3), 403-414 (2020)

30. W. Wereda, J. Woźniak, Social Sciences, 8(6), 177 (2019) 